\title{
Clinical debriefing during the COVID-19 pandemic: hurdles and opportunities for healthcare teams
}

\author{
Jody L. Stafford', Esther Leon-Castelao ${ }^{2} \mathbb{B}$, Albert J. Klein Ikkink³ ${ }^{3}$ Sigrun A. Qvindesland ${ }^{4}$, Munt Garcia-Font ${ }^{2} \mathbb{D}$,
} Demian Szyld ${ }^{5}$ (iD and Cristina Diaz-Navarro ${ }^{6^{*}}$ (i)

\begin{abstract}
The COVID-19 pandemic and the subsequent pressures on healthcare staff and resources have exacerbated the need for clinical teams to reflect and learn from workplace experiences. Surges in critically ill patients, the impact of the disease on the workforce and long term adjustments in work and life have upturned our normality. Whilst this situation has generated a new 'connectedness' within healthcare workers, it also continues to test our resilience. An international multi-professional collaboration has guided the identification of ongoing difficulties to effective communication and debriefing, as well as emerging opportunities to promote a culture of dialogue. This article outlines pandemic related barriers and new possibilities categorising them according to task management, teamwork, situational awareness and decision making. It describes their direct and indirect impact on clinical debriefing and signposts towards solutions to overcome challenges and, building on new bridges, advance team conversations that allow us to learn, improve and support each other.

This pandemic has brought clinical professionals together; nevertheless, it is essential to invest in further developing and supporting cohesive teams. Debriefing enables healthcare teams and educators to mitigate stress, build resilience and promote a culture of continuous learning and patient care improvement.
\end{abstract}

Keywords: COVID-19, Healthcare teams, Clinical debriefing, Non-technical skills, Human factors, Safety

\section{Background}

The COVID-19 pandemic continues to have a profound impact on healthcare workers, as it has posed unprecedented pressures and forced us all to adapt both professionally and personally to uncertainty and constant change during its peaks and troughs [1]. The need for healthcare institutions to support reflection and learning in the workplace is now more important than ever, yet rarely achieved [2]. The inclusion of clinical debriefing into routine safety behaviours offers an opportunity to reverse the status quo. This pandemic presents us with

\footnotetext{
* Correspondence: Cristina.Diaz-Navarro2@wales.nhs.uk

All authors participated in the concept and revision of the manuscript. ${ }^{6}$ Health Education and Improvement Wales, Cardiff, UK

Full list of author information is available at the end of the article
}

new hurdles to its implementation and delivery but also with new possibilities to further its use.

Debriefing is a conversation that promotes reflection and learning following an experience. In simulation education, it enables focussed discussions aiming to improve knowledge and performance [3]. Its incorporation into clinical practice allows the whole team to discuss real events, encourages reflection and allows a deep level of experiential learning. There is growing evidence that it contributes to improving clinical outcomes [4-6]. It contributes to building resilience, strengthening shared mental models and facilitating adaptation to changing circumstances, such as the ones faced in this crisis [79]. Clinical debriefing (CD) should encourage learning,

(c) The Author(s). 2021 Open Access This article is licensed under a Creative Commons Attribution 4.0 International License, which permits use, sharing, adaptation, distribution and reproduction in any medium or format, as long as you give appropriate credit to the original author(s) and the source, provide a link to the Creative Commons licence, and indicate if changes were made. The images or other third party material in this article are included in the article's Creative Commons licence, unless indicated otherwise in a credit line to the material. If material is not included in the article's Creative Commons licence and your intended use is not permitted by statutory regulation or exceeds the permitted use, you will need to obtain permission directly from the copyright holder. To view a copy of this licence, visit http://creativecommons.org/licenses/by/4.0/ The Creative Commons Public Domain Dedication waiver (http://creativecommons.org/publicdomain/zero/1.0/) applies to the data made available in this article, unless otherwise stated in a credit line to the data. 
patient safety and system improvement whilst providing psychological support to the whole team $[10,11]$.

COVID-19 has changed the way we live and work. Barriers to debriefing such as inadequate time, space and lack of standardisation, are well known [12]. Performance variability and continuous adaptation are at the core of complex ever-changing healthcare working environments [13], and markedly more so during the ongoing pandemic, which has prompted new ways of overcoming obstacles at individual, team and organisational levels, providing opportunities to address preexisting and new challenges.

The Education Committee of the TALK Foundation (www.talkdebrief.org) is a working group composed by international debriefing experts that coordinate and support $\mathrm{CD}$ implementation initiatives across a wide range of cultures, as our network currently includes 18 countries. Our experiences during this pandemic have led to the identification of new dynamics which affect the performance of CD. A collaborative interprofessional and international discussion process involving our local teams, together with an awareness of the latest evidence, have allowed us to reach a broad and practical perspective on the current situation. This article focuses on our observations of how COVID-19 affects clinical behaviours, its direct and indirect impact on CD performance, and the openings that we have capitalised on during this time.

We highlight arising opportunities and provide recommendations aiming to optimise team debriefing, engaging quality improvement whilst providing a supportive culture, enabling teams to better overcome current pandemic challenges as well as to prepare for a potentially fraught recovery period.

\section{Challenges and new opportunities for clinical debriefing during a pandemic: considerations through the lens of a non-technical skills framework}

The impact of COVID-19 on human factors is all encompassing, disrupting the way we behave, communicate, learn and reflect $[1,14]$. Individuals and teams are at the core of healthcare systems and their abilities and limitations are key determinants of overall performance [15]. CD allows us to recognise how new conditions affect the way we work, take steps to support teams and improve together whilst fostering a healthcare culture of resilience and safety $[8,16]$.

In this article, we discuss how this pandemic has disrupted our performance across four categories: task management, team working, situation awareness and decision making. Building on our collective experience, we consider how this turmoil continues to affect our clinical practice as well as the subsequent debriefings, and share proposals for overcoming difficulties whilst making the most out of new opportunities. We have organised the issues identified, their implications for $\mathrm{CD}$ and our recommendations (Table 1) according to a non-technical skills (NTS) framework, as this taxonomy provides a befitting standardised approach to the observation and improvement of workplace behaviours both in clinical and simulation environments [17-20].

\section{Task management}

Task management refers to how we assign and organise activities in order to achieve our goals. It encompasses four elements: planning and preparation, prioritisation, maintenance of standards and utilisation of resources [18]. COVID-19 has mandated a profound change to the way we behave and perform routine duties in healthcare practice.

For instance, maintaining infection control standards has become an overarching priority, preceding patient care delivery. In areas with potentially infectious patients, such as emergency departments or acute admission wards, staff must wear comprehensive personal protective equipment (PPE) before initiating aerosol generating procedures (AGP), even if these are life-saving [21]. This means that if a patient in those locations requires cardiopulmonary resuscitation (CPR), all staff must focus on donning (putting on) PPE before providing active patient care. Delaying CPR due to infection control measures may challenge our core values and have an emotional impact which could make a subsequent debriefing complex.

In this case, as in difficult post-simulation debriefing [22], access to experienced facilitators with advanced training may be crucial to a successful learning conversation, considering the "dynamic balancing act" of providing a safe psychological environment [23]. In our exposure to debriefing multi-professional teams following critical interventions which have been delayed by necessary infection precautions, it has been essential to provide early support to team members, reassurance that the right priorities have been established and freedom for different team perspectives to become explicit in order to identify constructive and collaborative ways forward.

New tasks and resources introduced in order to maintain patient and staff safety include wearing visors and tight-fitting face masks or respirators, which are uncomfortable and hinder communication. In our experience, these visual and auditory barriers markedly affect information gathering and exchange during clinical processes and particularly during debriefing, leading to team members not hearing or misunderstanding each other. However, as team members doff (take it off) and change to lower protection PPE, they move away from the original 
Table 1 COVID-related changes affecting clinical behaviour, their implications for CD, solutions and opportunities

\begin{tabular}{|c|c|c|c|}
\hline $\begin{array}{l}\text { COVID related changes affecting } \\
\text { clinical behaviours }\end{array}$ & NTS category & $\begin{array}{l}\text { Consequences/complexities affecting } \\
\text { clinical debriefing }\end{array}$ & Solutions and new opportunities \\
\hline $\begin{array}{l}\text { Infection control measures prior to all } \\
\text { clinical interactions }\end{array}$ & $\begin{array}{l}\text { Task } \\
\text { management }\end{array}$ & $\begin{array}{l}\text { Potential patient care delay } \\
\text { Emotional consequences, complex CD }\end{array}$ & Debrief supported by expert facilitators \\
\hline Wearing PPE & & $\begin{array}{l}\text { Visual and auditory limitations } \\
\text { Teams separate at the time of removing } \\
\text { PPE (doffing) }\end{array}$ & $\begin{array}{l}\text { Early planning of debriefing } \\
\text { Pre-set regular debriefing } \\
\text { Agree CD time during team briefing }\end{array}$ \\
\hline Team distribution & Teamwork & $\begin{array}{l}\text { Divided teams and isolated clinical areas, } \\
\text { different COVID exposure }\end{array}$ & Virtual (online) debriefing \\
\hline Staff shortages & & $\begin{array}{l}\text { Sickness, self-isolation, shielding } \\
\text { Increased workload } \\
\text { Lack of time } \\
\text { Exhaustion }\end{array}$ & $\begin{array}{l}\text { Gain institutional support to prioritise } \\
\text { safety behaviours such as CD } \\
\text { Engage staff by sharing the purpose and } \\
\text { benefit of debriefing } \\
\text { Short and structured debriefing }\end{array}$ \\
\hline Redeployment & & $\begin{array}{l}\text { Increased critical care demand } \\
\text { Reorganisation of services }\end{array}$ & $\begin{array}{l}\text { Collaborate with debriefing experts } \\
\text { Embed new safety practice (debriefing) } \\
\text { Promote resilience }\end{array}$ \\
\hline Leadership challenges & & $\begin{array}{l}\text { Shifting goals and guidelines, staff } \\
\text { uncertainty }\end{array}$ & $\begin{array}{l}\text { Identification of needs via debriefing } \\
\text { Reinforcement of good practice }\end{array}$ \\
\hline $\begin{array}{l}\text { Limited direct contact with patient, } \\
\text { relatives and staff }\end{array}$ & $\begin{array}{l}\text { Situation } \\
\text { awareness }\end{array}$ & $\begin{array}{l}\text { Hindered information gathering } \\
\text { Stress and frustration }\end{array}$ & $\begin{array}{l}\text { Ensure psychological safety: } \\
\text { supportive/empathetic debriefing }\end{array}$ \\
\hline Changes to practice and environment & & $\begin{array}{l}\text { Rapid change, need to gain familiarity with } \\
\text { new ways of working }\end{array}$ & $\begin{array}{l}\text { Opportunity for meaningful } \\
\text { interprofessional engagement with CD }\end{array}$ \\
\hline Self-awareness & & $\begin{array}{l}\text { Reduced resilience } \\
\text { Stress and exhaustion }\end{array}$ & $\begin{array}{l}\text { Highlight wellbeing benefits of supportive } \\
\text { debriefing }\end{array}$ \\
\hline $\begin{array}{l}\text { Changes to diagnostic and treatment } \\
\text { options }\end{array}$ & $\begin{array}{l}\text { Decision- } \\
\text { making }\end{array}$ & $\begin{array}{l}\text { Available/accessible resources } \\
\text { Changes to local guidelines might } \\
\text { generate self-doubt } \\
\text { Risk v benefit during pandemic }\end{array}$ & $\begin{array}{l}\text { Online multi-professional } \\
\text { Debriefing to align decisions } \\
\text { Share debriefing outcomes } \\
\text { Consider the long term }\end{array}$ \\
\hline
\end{tabular}

clinical area and team. Ensuring that CD is carried out in these circumstances requires engaging the full team in early planning and identification of an appropriate time and place, and will benefit from organisational support $[2,13]$.

We propose that a regular time and place for debriefing conversations is scheduled whenever possible, as this promotes peer connection and wellbeing $[16,24]$. For instance, some of our teams have established routine end of shift debriefing sessions prior to handover. Alternatively, the time for $\mathrm{CD}$ can be arranged during team briefing in areas such as operating theatres or critical care $[24,25]$.

\section{Teamwork}

Teamwork alludes to collaborative task completion and team member satisfaction and includes coordination of activities, exchange of information, leadership and followership, identifying capabilities and mutual support. The demands of managing COVID-19 have led to a constant state of flux, including large-scale restructuring of the workforce, resulting in the disruption of team dynamics $[1,14]$.

Physical barriers and varying levels of PPE disrupt teamwork albeit increasing safety [26]. Ensuing challenges to communication, including in-situ debriefing, must be acknowledged. Additionally, team distribution has been altered, as clinical areas have been divided into zones determined by infection risk and proximity to AGP. This separates and isolates staff, hindering activity coordination, information exchange and CD. As COVID-19 has rapidly advanced the use of telecommunication, we recommend establishing virtual debriefing sessions, which help build team resilience [8].

Online debriefing eliminates social distancing concerns and is particularly useful when signposting to further learning resources; however, this conveys unique sociocognitive challenges which require tailored strategies, for example expressing appreciation, promoting inclusivity and explicitly acknowledging team members, as described by Cheng and colleagues [27].

Staff shortages relating to sickness, post-exposure quarantine, post travel self-isolation or shielding from infection continue to compound our challenges. High pressures on elective and emergency services related to increasing patient complexity, delayed treatments and escalating waiting lists [28] may decrease the uptake of debriefing processes. However, these high pressures might make overworked and exhausted staff more likely to benefit from shared reflective practice $[8,9]$. Gaining 
institutional support to ensure that safety behaviours are prioritised at times of crisis is paramount [2, 13]. Clinical debriefing leads should disseminate the benefits of debriefing for improvement, wellbeing and resilience [4$9,17,24]$ in order to encourage staff to engage with debriefing processes.

We suggest that $\mathrm{CD}$ sessions are brief and follow a structure familiar to the team such as TALK $^{\odot}$ [29], DISCERN [30], INFO [31], TeamSTEPPS [32] or DISCOVER-PHASE [33].

In our case, we have implemented $\mathrm{TALK}^{\odot}$ for $\mathrm{CD}$, as it is an easy, inclusive and scalable way to debrief, supported by short standardised training sessions (less than $2 \mathrm{~h}$ ). This initiative has been actively supported at an institutional level and well received by multi-professional staff.

The disruption of routine services and staff reorganisation to accommodate the surge in critically ill patients, and further adaptations to accommodate increasing service demands, have disrupted healthcare silos and normal delivery of care [28]. This redirection has resulted in staff rapidly adapting to cope with emerging needs: initially, working groups such as 'Proning Teams' needed to be assembled to learn and perform unfamiliar tasks at a high standard [34]; more recently, clinical personnel have been mobilised to deliver vaccination programmes [35]. Whilst these shared purposes are largely embraced, arising challenges can be eased through co-learning during debriefing conversations. New collaboration opportunities may emerge as $\mathrm{CD}$ expertise becomes available through staff redistribution or changes to service delivery. We propose that redeployed experts such as simulation educators, wellbeing staff or psychologists are introduced to the principles of $\mathrm{CD}$ and use their preexisting skills to facilitate team debriefing. As an example, educators have volunteered to support vaccination efforts, placing themselves in an ideal position to facilitate $C D$ in these new teams. This experience might later allow the integration of $\mathrm{CD}$ training within simulation settings, which will in turn promote future workforce teams to share reflections through debriefing practice.

Rapid changes in local and national guidelines due to new knowledge, infection prevalence and resource prioritisation translate into shifting goals, staff uncertainty and leadership challenges. This provides an opportunity to promote debriefing at a healthcare management level by highlighting organisational advantages of $\mathrm{CD}$ : it offers the opportunity to involve all staff in identifying emerging needs and system strengths and weaknesses [13], as well as to promote a culture of safety whilst fostering staff resilience $[8,12]$. For instance, routine debriefing following the introduction of new infection risk zones allows teams to deal with practical difficulties, engaging all staff in monitoring and adapting to this reconfiguration.

\section{Situation awareness}

Situation awareness (SA) applies to overall awareness of patient care and the environment where it takes place [18], including any relevant aspects such as patient's condition and evolution, team, resources and time as well as how we perceive relevant cues, interpret their meaning, build a mental model, and predict what could happen next [36]. Hence, SA incorporates the processes of gathering information, recognising and understanding and anticipating, which have been threatened by the extensive disruption caused by this pandemic, as it continues to affect team and individual performance [1,28].

We have experienced restrictions to contact with patients, relatives and colleagues as a consequence of efforts to limit viral spread and to conserve PPE. For example, an anaesthetist working in a low infection risk area can only access higher risk zones after wearing comprehensive PPE and can only return to lower risk areas after showering and changing into clean clothing; as a consequence, visits across areas are minimised, which may lead to loss of early access to important preoperative information such as observing the patient's anatomy to assess their airway.

Moreover, access to information is hindered by staff working in isolation, lack of straightforward patientclinician interaction and minimal opportunities to communicate with relatives other than telephonically. Information gathering may be thwarted further by stress and tiredness. We should acknowledge that in this context, $\mathrm{CD}$ is likely to be affected by ongoing frustrations. A supportive and empathetic approach is essential in order to sustain psychological safety during debriefing [23].

Rapidly changing environments and practice pose an extraordinary demand on SA and may give rise to clinical errors. Gaining familiarity with new ways of working will require a concerted interprofessional effort [14], which may foster a renewed engagement with meaningful $C D$ as an avenue to move forward cohesively [12]. For instance, the establishment of regular online debriefing has allowed teams to share new pathways, set up innovative information streams and regain a sense of community whilst adhering to social distancing rules, which in turn has reinforced the usefulness of $\mathrm{CD}$.

Self-awareness decreases when faced with cognitive overload, stress and burnout; for teams and individuals to perform optimally during this protracted crisis, they must look after themselves and each other [14]. This also offers a fertile ground to promote debriefing, as it allows the identification of vulnerabilities and provides the opportunity for all staff and clinical leads to demonstrate solidarity and promote wellbeing $[8,24,37]$. 


\section{Decision-making}

Decision-making involves selecting a course of action by identifying options, assessing risks and benefits, carrying out an appropriate action and re-evaluating. This balance has been hampered during this crisis by new priorities as well as different considerations in risk versus benefit analyses.

Diagnostic and treatment options for patients both with and without COVID-19 have been affected [28]. Resource availability and accessibility may promote conservative treatment strategies, reduce elective procedures and lead to demanding conversations with patients and colleagues. We recommend exploring virtual multi professional debriefing sessions to facilitate collective prioritisation and decision alignment [16, 27]. Sharing outcomes and lessons from these conversations may guide to shape planning and future strategies [2, 24].

\section{Conclusion}

The COVID-19 pandemic has created many difficulties for healthcare teams over the last year which has impacted on debriefing processes. New challenges and barriers to communication have forced teams and individuals to adapt their practice.

This article applies the NTS taxonomy as a lens to consider some of the challenges of this pandemic and highlight their direct and indirect impact on CD. It also identifies possible solutions and opportunities based on the latest evidence which associates $\mathrm{CD}$ experiences during this crisis with increased team resilience and wellbeing. This new context should stimulate a renewed interest to embed clinical debriefing into everyday practice as a way of collaborative reflection and learning within individuals, teams and organisations. The recognition of local challenges through $C D$ will guide system improvement and staff support measures over the foreseeable future.

The pandemic has brought clinical professionals together; it is essential to nurture and maintain these reinvigorated relationships across organisations and invest in further developing cohesive teams. Debriefing is a tool for healthcare teams and educators to provide emotional support, mitigate stress and ultimately promote a culture of continuous learning and improved patient care.

\section{Acknowledgements}

The TALK Foundation (legacy to the TALK ${ }^{\odot}$ Project) registered with the UK Charity Commission under Registration Number 1177093.

\section{Authors' contributions}

All authors participated in the concept and revision of the manuscript. The author(s) read and approved the final manuscript.

\section{Funding}

The TALK ${ }^{\odot}$ project has received funding from the European Union's Horizon 2020 research and innovation programme under the Marie Skłodowska-Curie grant agreement No 734753. However, this article reflects only the author's view and that the Research Executive Agency of the European Commission is not responsible for any use that may be made of the information it contains.

Availability of data and materials

Not applicable

\section{Declarations}

Ethics approval and consent to participate

Ethical approval was not required in the preparation of this article

Consent for publication

Not applicable

Competing interests

The authors declare that they have no competing interests

\section{Author details}

'Department of Perfusion/Cardiothoracic Surgery, Cardiff and Vale University Health Board, Cardiff, UK. ${ }^{2}$ Clinical Simulation Laboratory, Faculty of Medicine and Healthcare Sciences, University of Barcelona, Barcelona, Spain.

${ }^{3}$ Wenckebach Simulation Center for Training, Education and Research, University Medical Center Groningen, Groningen, The Netherlands.

${ }^{4}$ Department of Education, Stavanger University Hospital, Stavanger, Norway. ${ }^{5}$ Center for Medical Simulation, Boston, MA, USA. ${ }^{6}$ Health Education and Improvement Wales, Cardiff, UK.

Received: 4 March 2021 Accepted: 24 August 2021

Published online: 15 September 2021

References

1. Shanafelt T, Ripp J, Trockel M. Understanding and Addressing Sources of Anxiety Among Health Care Professionals During the COVID-19 Pandemic. JAMA. 2020;323(21):2133-4.

2. Arriaga AF, Szyld D, Pian-Smith MCM. Real-Time Debriefing After Critical Events: Exploring the Gap Between Principle and Reality. Anesthesiol Clin. 2020;38(4):801-20. https://doi.org/10.1016/j.anclin.2020.08.003. Epub 2020 Oct 13. PMID: 33127029; PMCID: PMC7552980

3. Tavares W, Eppich W, Cheng A, Miller S, Teunissen PW, Watling CJ, et al. Learning Conversations: An Analysis of the Theoretical Roots and Their Manifestations of Feedback and Debriefing in Medical Education. Acad Med. 2020;95(7):1020-5.

4. Couper K, Salman B, Soar J, Finn J, Perkins GD. Debriefing to improve outcomes from critical illness: a systematic review and meta-analysis. Intensive Care Med. 2013;39(9):1513-23. https://doi.org/10.1007/s00134013-2951-7.

5. Wolfe H, Zebuhr C, Topjian AA, Nishisaki A, Niles DE, Meaney PA, et al. Interdisciplinary ICU cardiac arrest debriefing improves survival outcomes*. Crit Care Med. 2014;42(7):1688-95. https://doi.org/10.1097/CCM. 0000000000000327.

6. Cheng A, Nadkarni VM, Mancini MB, Hunt EA, Sinz EH, Merchant RM, et al. Resuscitation education science: educational strategies to improve outcomes from cardiac arrest: a scientific state- ment from the American Heart Association. Circulation. 2018;138(6):e82-122. https://doi.org/10.1161/ CIR.0000000000000583.

7. Tannenbaum SI, Cerasoli CP. Do Team and Individual Debriefs Enhance Performance? A Meta-Analysis. Hum Factors. 2013;55(1):231-45. https://doi. org/10.1177/0018720812448394.

8. Azizoddin, D. R., Gray, K. V., Dundin, A., \& Szyld, D. (2020). Bolstering clinician resilience through an interprofessional, web-based nightly debriefing program for emergency departments during the COVID-19 pandemic. J Interprof Care. Available from:https://www.tandfonline.com/doi/full/https:// doi.org/10.1080/13561820.2020.1813697

9. Chen J, Bamberger PA, Song Y, Vashdi DR. The effects of team reflexivity on psychological well-being in manufacturing teams. J Appl Psychol [Internet]. 2018;103(4):443-62. Available from: https://pubmed.ncbi.nlm.nih.gov/2923 9644/. https://doi.org/10.1037/apl0000279.

10. Diaz-Navarro, C., Hadfield, A., \& Pierce, S. (2014). TALK Debriefing. Retrieved September 3, 2020, from https://www.talkdebrief.org/startingtotalk 
11. Coggins, A., Zaklama, R., Szabo, R., Diaz-Navarro, C., Scalese, R., Krogh, K., \& Eppich, W. (2020). Twelve tips for facilitating and implementing clinical debriefing programmes. Med Teach. https://doi.org/10.1080/0142159X.202 0.1817349

12. Twigg S. Clinical event debriefing: a review of approaches and objectives. Curr Opin Pediatr. 2020;32(3):337-42. https://doi.org/10.1097/MOP. 0000000000000890.

13. Hollnagel E, Wears RL, Braithwaite J. From Safety-I to Safety-II: A White Paper. The Resilient Health Care Net: Published simultaneously by the University of Southern Denmark, University of Florida, USA, and Macquarie University, Australia; 2015.

14. Albolino S, Dagliana G, Tanzini M, Toccafondi G, Beleffi E, Ranzani F, et al. Human factors and ergonomics at time of crises: the Italian experience coping with COVID-19. Int J Qual Health Care. 2021;33(1):mzaa049. https:// doi.org/10.1093/intqhc/mzaa049 PMID: 32400879; PMCID: PMC7239148.

15. St.Pierre M, Hofinger $G$, Simon R. Crisis Management in Acute Care Settings, Anesthesia \& Analgesia. Cham: Springer International Publishing; 2016. https://doi.org/10.1007/978-3-319-41427-0.

16. Servotte J-C, Welch-Horan TB, Mullan P, Piazza J, Ghuysen A, Szyld D. 'Development and implementation of an end-of-shift clinical debriefing method for emergency departments during COVID-19', Advances in Simulation. Adv Simul. 2020;5(1):32. https://doi.org/10.1186/s41077-020-001 50-0.

17. Flin R. (2018) Enhancing Safety Performance: Non-technical Skills and a Modicum of Chronic Unease. In: Bieder C., Gilbert C., Journé B., Laroche H. (eds) Beyond Safety Training. SpringerBriefs in Applied Sciences and Technology. Springer, Cham. https://doi.org/10.1007/978-3-319-65527-7_6

18. Flin R, Patey R, Glavin R, Maran N. Anaesthetists' non-technical skills. Br J Anaesth. 2010;105(1):38-44. https://doi.org/10.1093/bja/aeq134.

19. Neuhaus, C., Lutnæs, D.E. \& Bergström, J. Medical teamwork and the evolution of safety science: a critical review. Cogn Tech Work 22, 13-27 (2020). https://doi.org/https://doi.org/10.1007/s10111-019-00545-8, 1

20. Yule S, Smink DS. Nontechnical Skill Countermeasures for Pandemic Response. Annals of Surgery. 2020;272(3):e213-5. https://doi.org/10.1097/ SLA.0000000000004107.

21. Nolan JP, Monsieurs KG, Bossaert L, Böttiger BW, Greif R, Lott C, et al. European Resuscitation Council COVID-19 guidelines executive summary. Resuscitation. 2020;153:45-55.

22. Grant, V. J., Robinson T., Catena H., Eppich W., Cheng A. (2018) 'Difficult debriefing situations: A toolbox for simulation educators', Medical Teacher. Informa UK Ltd., O(0), pp. 1-10. https://doi.org/10.1080/0142159X.2018.14 $68558,40,7$.

23. Kolbe M, Eppich W, Rudolph J, et al. Managing psychological safety in debriefings: a dynamic balancing act. BMJ Simul Technol Enhanced Learn. 2020:6:164-71.

24. Rock, L. K. et al. (2020) "'Circle Up": Workflow adaptation and psychological support via briefing, debriefing, and peer support', Nejm Catalyst Innovations in Care Delivery, p. https://doi.org/10.1056/CAT.20.0240.

25. Vickers R. Five steps to safer surgery. Ann R Coll Surg Engl. 2011;93(7):501-3. https://doi.org/10.1308/147870811X599334.

26. Arabi, Y.M., Azoulay, E., Al-Dorzi, H.M. et al. How the COVID-19 pandemic will change the future of critical care. Intensive Care Med 47, 282-291 (2021). https://doi.org/10.1007/s00134-021-06352-y, 3

27. Cheng, A., Kolbe, M., Grant, V., Eller S., Hales R., Symon B., Griswold S., Eppich W. A practical guide to virtual debriefings: communities of inquiry perspective. Adv Simul 5, 18 (2020). https://doi.org/10.1186/s41077-02000141-1

28. Gardner T, Fraser C. Longer waits, missing patients and catching up. The Health Foundation website. Available from: https://www.health.org.uk/ news-and-comment/charts-and-infographics/how-is-elective-care-copingwith-the-continuing-impact-of-covid-19. Posted 13 April 2021, Accessed 2 June 2021.

29. Diaz-Navarro C, Leon-Castelao E, Hadfield A, Pierce S, Szyld D. Clinical debriefing: TALK@ to learn and improve together in healthcare environments. Trends Anaesth Crit Care. 2021 (In Press) Available from: https://linkinghub.elsevier.com/retrieve/pii/S2210844021001052. https://doi. org/10.1016/j.tacc.2021.07.004.

30. Mullan PC, Wuestner E, Kerr TD, Christopher DP, Patel B. Implementation of an in situ qualitative debriefing tool for resuscitations. Resuscitation. 2013; 84(7):946-51 [cited 2017 May 31]. Available from: http://www.ncbi.nlm.nih. gov/pubmed/23266394.
31. Rose $\mathrm{S}$, Cheng A. Charge nurse facilitated clinical debriefing in the emergency department. CJEM. 2018;20(5):781-5. Available from: https:// www.cambridge.org/core/product/identifier/S148180351800369X/type/ journal_article. https://doi.org/10.1017/cem.2018.369.

32. Agency for Healthcare Research and Quality, United States.TeamSTEPPS ${ }^{\oplus} 2.0$ Pocket Guide AHRQ Pub. No. 14-0001-2, Revised December 2013. Available from https://www.ahrq.gov/sites/default/files/wysiwyg/professionals/educa tion/curriculum-tools/teamstepps/instructor/essentials/pocketguide.pdf

33. Welch-Horan TB, Lemke DS, Bastero P, Leong-Kee S, Khattab M, Eggers J, et al. 'Feedback, reflection and team learning for COVID-19: development of a novel clinical event debriefing tool. BMJ Simul Technol Enhanced Learn, p. bmjstel-2020-000638. 2020;7(1):54-7. https://doi.org/10.1136/bmjstel-2020000638.

34. Kulkarni S. The bone prone team. J Clin Orthop Trauma. 2020;11(Suppl 4): S446-7.

35. Mills MC, Salisbury D. The challenges of distributing COVID-19 vaccinations. EClinicalMedicine. 2021;31:100674. https://doi.org/10.1016/j.eclinm.2020.1 00674.

36. Gillman LM, et al., editors. Trauma Team Dynamics, Trauma Team Dynamics. Cham: Springer International Publishing; 2016. https://doi.org/10.1007/ 978-3-319-16586-8.

37. Dieckmann P, Torgeirsen K, Qvindesland SA, Thomas L, Bushell V, Langli Ersdal $\mathrm{H}$. The use of simulation to prepare and improve responses to infectious disease outbreaks like COVID-19: practical tips and resources from Norway, Denmark, and the UK. Advances in Simulation. 2020;5(1):3. https:// doi.org/10.1186/s41077-020-00121-5.

\section{Publisher's Note}

Springer Nature remains neutral with regard to jurisdictional claims in published maps and institutional affiliations.

Ready to submit your research? Choose BMC and benefit from:

- fast, convenient online submission

- thorough peer review by experienced researchers in your field

- rapid publication on acceptance

- support for research data, including large and complex data types

- gold Open Access which fosters wider collaboration and increased citations

- maximum visibility for your research: over $100 \mathrm{M}$ website views per year

At $\mathrm{BMC}$, research is always in progress.

Learn more biomedcentral.com/submissions 